\title{
A longitudinal study of maternal anthropometric changes in normal weight, overweight and obese women during pregnancy and postpartum
}

\author{
Hora Soltani*† and Robert B. Fraser \\ University Department of Obstetrics and Gynaecology, Clinical Sciences Centre, Northern General Hospital, \\ Sheffield S5 7AU, UK
}

(Received 5 May 1999 - Revised 1 October 1999 - Accepted 25 November 1999)

\begin{abstract}
Many women associate one or more of their pregnancies with the development of adult obesity. Such an association has not been fully explored. This longitudinal study examines the changes in maternal anthropometric indices during pregnancy and postpartum. Seventy-seven pregnant subjects were investigated longitudinally at about 13, 25 and 36 weeks gestation, of whom fortyseven continued taking part into the postpartum period. Maternal weight, height and skinfold thickness (triceps, biceps, subscapular, suprailiac and mid thigh) were measured at each visit. Maternal fat mass was estimated from the conversion of the first four skinfold thicknesses. Maternal waist and hip circumferences were also measured at the first visit and 6 weeks and 6 months postpartum. Weight and fat gain during pregnancy (13-36 weeks gestation) was 10.9 $($ SD 4.7$) \mathrm{kg}$ and 4.6 (SD 3.3) $\mathrm{kg}(P<0.001)$ respectively. A significant increase in fat mass from 13 weeks gestation to 6-months postpartum was observed (2.6 (SD 4.5), $P<0.001$ ). The increased weight at 6-months postpartum, however, was not statistically significant $(1 \cdot 1$ (SD 6.0) kg, $P=0 \cdot 20$ ). Based on BMI in early pregnancy, the subjects were divided into groups of underweight, normal weight, overweight and obese. The last three groups were compared using ANOVA. The obese group showed a significant difference in the pattern of changes in the skinfold thickness, waist : hip ratio and fat mass at the postpartum period, in comparison with the other two groups. In conclusion, there is a tendency in the obese group to develop central obesity at the postpartum period.
\end{abstract}

Maternal anthropometry: Obesity: Pregnancy

Obesity has long been recognised as a risk factor for the development of a variety of diseases such as diabetes mellitus and cardiovascular disease (Jung, 1997). In particular in women of child-bearing age, obesity predisposes towards impaired glucose tolerance and gestational diabetes mellitus (Solomon et al. 1997). This nutritional disorder is not only common but also increasing in prevalence (Department of Health, 1997). Identification of factors contributing to obesity may be useful in planning preventative policies.

It is well known that there is more to obesity than the actual amount of excess weight. The adverse metabolic effects of obesity are related to the distribution of the excess fat. Central fat deposition provokes more disordered glucose tolerance than peripheral fat distribution in subjects with identical BMI (Kissebah \& Krakower, 1994). Many women relate the onset of their obesity to one or more of their pregnancies (Ohlin \& Rossner, 1990). Previous studies suggest that during pregnancy most women in the developed world accumulate subcutaneous fat which contributes to their overall net weight gain (Taggart et al. 1967; Sohlström \& Forsum, 1995). A study by Muscati et al. (1996) on wellnourished women showed that pregnancy weight gain explains $65.2 \%$ of the variability in postpartum weight retention but very little $(4.7 \%)$ in infant birth weight. The results of a comprehensive review by Harris \& Ellison (1997) suggest that there is still a considerable amount of controversy on the impact of pregnancy on maternal obesity. In a retrospective study of 243 English mothers by Harris et al. (1997) maternal prepregnant BMI was found to be an important determinant factor in long-term weight gain during the reproductive cycle. The body of knowledge on the component of the weight changes during pregnancy and postpartum is even more limited. The majority of these studies (Forsum et al. 1988; Sadurskis et al. 1988; Sohlström \& Forsum, 1995) have been conducted on a small

\footnotetext{
Abbreviations: NW, normal weight; OB, obese; OW, overweight; UW, underweight.

* Corresponding author: Dr Hora Soltani, fax +44(0)114222 9856, email h.soltani@sheffield.ac.uk

† Present address: East Riding Health Authority, Grange Park Lane, Willerby, East Yorkshire HU10 6DT, UK, fax +44 (0) 1482 6720062, email h.soltani@eriding-ha.northy.nhs.uk
} 
number of women who were either normal-weight women or maternal BMI was not considered as a confounding factor in the design of the study. This present longitudinal study was designed to investigate the pattern of changes in weight gain and fat distribution during pregnancy and postpartum and whether this differed by maternal BMI measured in the first trimester.

\section{Subjects and methods}

Seventy-seven pregnant women participated in the study through an interview at their first visit to the antenatal clinics of the Northern General Hospital, Sheffield, UK. Fifty-one of these women continued participation at 6 weeks and forty-seven at 6 months postpartum.

Based on $\mathrm{BMI}=$ weight $/$ height $^{2}$ in early pregnancy, women were classified into four groups: underweight (UW, $\mathrm{BMI}<19 \cdot 8$ ), normal weight (NW, $19 \cdot 8 \leqslant \mathrm{BMI} \leqslant 26)$, overweight $(\mathrm{OW}, 26<\mathrm{BMI} \leqslant 29)$ and obese $(\mathrm{OB}, \mathrm{BMI}>9)$. The criteria for the classification of the BMI groups are those of the Institute of Medicine (1990).

Serial measurements of anthropometry including fat mass were made on three occasions during pregnancy (mean of $13,25,36$ weeks) and on two occasions after delivery (6 weeks and 6 months).

Birth weight and placenta weight were obtained from the patients' notes. Maternal fat mass (FM) was estimated using skinfold thickness measurements. Skinfold thickness was measured by single observer with Holtain callipers (Holtain Ltd, Crymych, UK) exerting a constant pressure of $10 \mathrm{~g} / \mathrm{mm}^{2}$. Each measurement made in triplicate on the left side of the body, the results were then averaged. The skinfold thicknesses were taken to the nearest $0.2 \mathrm{~mm}$, at the triceps, biceps, subscapular, suprailiac and mid thigh sites. Each skinfold thickness was measured as described by Taggart et al. (1967). To have an estimation of the reliability of the measurements, six non-pregnant women (three women with $\mathrm{BMI} \leqslant 26$ and three with $\mathrm{BMI}>26$ ) were measured on four occasions in the same day. The $\mathrm{CV}$ of the measurements on the same subjects is shown in Table 1.

The sum of the first four skinfold thicknesses measured was used to estimate body density using the equation of Durnin \& Womersley (1974). Maternal fat mass was then derived using specific equations to convert body density to fat mass. Pregnancy-specific equations have been developed by Van Raaij et al. (1988) to convert maternal body density to fat mass. These equations account for the altering

Table 1. Coefficients of variation (\%) of skinfold thicknesses in six non-pregnant women measured on four occasions on the same day

\begin{tabular}{lccc}
\hline & \multicolumn{2}{c}{ BMI } & Total women \\
\cline { 2 - 3 } & $\leqslant 26(n 3)$ & $\geqslant 26(n 3)$ & $(n)$ \\
\hline Triceps & 2.9 & 3.3 & 3.1 \\
Biceps & 4.6 & 11.9 & 8.2 \\
Subscapular & 7.5 & 6.4 & 7.0 \\
Suprailiac & 5.8 & 8.3 & 7.3 \\
Mid thigh & 2.8 & 2.1 & 2.4 \\
Total skinfold thickness & 1.6 & 2.3 & 2.1 \\
\hline
\end{tabular}

composition of the maternal fat free mass components through pregnancy. These equations are as follows for 12, 24 and 36 weeks gestation respectively:

$$
\begin{aligned}
& F M=W / 100 \times(497 / D-452 \cdot 3), \\
& F M=W / 100 \times(504 \cdot 3 / D-460 \cdot 4), \\
& F M=W / 100 \times(516 \cdot 3 / D-473 \cdot 7),
\end{aligned}
$$

where FM is the fat mass, $\mathrm{W}$ is the body weight and D is the body density. At the postpartum period, Siri's (1956) equation was used to calculate maternal fat mass:

$$
\text { Body fat }(\%)=((495 / \text { body density })-450) \times 100 \text {. }
$$

The changes in fat distribution were studied by comparison of individual skinfold thicknesses as well as using the index of waist : hip ratio, measured in early pregnancy and postpartum. Waist measurements were made at the level of umbilicus directly on the skin, while the subject was standing erect. Maternal body weight was measured in light clothing (without shoes) with a Seca 760 scale (Cranlea, Birmingham, UK). Maternal height was measured (without shoes) with the heels together and with the Frankfurt plane of the head in a horizontal position (World Health Organization, 1987).

We classified the subjects into social classes based on their occupation, using the criteria established by the UK Office of Population Censuses and Surveys (1991).

The study was approved by the Ethics Committee of the North Sheffield Hospitals. All the subjects signed an informative consent form.

\section{Statistical analysis}

Data were analysed using Statistical Package for Social Sciences (SPSS for Windows 95/NT, version 7.5.1, 1996, SPSS Inc., Chicago, USA). Mean values and standard deviations are reported. $P$ values less than 0.05 were considered significant and the significance levels quoted are two-sided. Normality of the distribution of all the parameters was confirmed using the Kolmogrov-Smirnov test before statistical analysis for inferences.

Summary measures for each variable were calculated and compared among the groups using one-way ANOVA (Tukey's honestly significant test). Summary measures (Matthews et al. 1990) allows comparison of the selected features of each subject over time. The summary measures calculated for weight and fat mass were: rate of changes in early and late pregnancy, the absolute changes from 13- to 36-weeks gestation, from 36-weeks gestation to 6-months postpartum and finally from 13 -weeks gestation to 6-months postpartum.

\section{Results}

Characteristics of the subjects are presented in Table 2. The majority of the subjects $(76 \%)$ were non-smokers. The rates of breast-feeding at 6-weeks and 6-months postpartum were 26/51 and 4/47 respectively. 
Table 2. Characteristics of the whole study group and each BMI group

(Mean values and standard deviations)

\begin{tabular}{|c|c|c|c|c|c|c|c|c|}
\hline & \multicolumn{2}{|c|}{$\begin{array}{l}\text { Normal weight } \\
\quad(n 29)\end{array}$} & \multicolumn{2}{|c|}{$\begin{array}{l}\text { Overweight } \\
\quad(n 23)\end{array}$} & \multicolumn{2}{|c|}{$\begin{array}{l}\text { Obese } \\
(n 25)\end{array}$} & \multicolumn{2}{|c|}{$\begin{array}{l}\text { Total } \\
(n 77)\end{array}$} \\
\hline & Mean & SD & Mean & SD & Mean & SD & Mean & SD \\
\hline Early pregnancy weight (kg) & $60 \cdot 8$ & 5.6 & $72 \cdot 0$ & 5.9 & 93.0 & $10 \cdot 6$ & 73.0 & $16 \cdot 8$ \\
\hline Height $(\mathrm{m})$ & 1.64 & 0.06 & 1.61 & 0.05 & 1.64 & 0.06 & 1.63 & 0.08 \\
\hline $\operatorname{BMI}\left(\mathrm{kg} / \mathrm{m}^{2}\right)$ & $22 \cdot 7$ & 1.3 & $27 \cdot 7$ & 1.4 & 34.5 & 3.54 & 27.4 & 5.9 \\
\hline Waist : hip ratio at first visit & 0.88 & 0.06 & 0.92 & 0.08 & 0.96 & 0.08 & 0.92 & 0.08 \\
\hline Age at first visit (years) & $26 \cdot 44$ & $5 \cdot 32$ & 26.91 & 4.50 & $27 \cdot 68$ & 3.83 & $26 \cdot 71$ & 4.77 \\
\hline Gravida & 1.86 & 1.27 & 2.2 & 1.37 & 2.44 & $1 \cdot 16$ & 2.08 & $1 \cdot 12$ \\
\hline Parity & 0.55 & 0.87 & 0.81 & 0.75 & 1.00 & 0.96 & 0.78 & 0.86 \\
\hline Gestational age at first visit (weeks) & $13 \cdot 24$ & 1.55 & 13.04 & 1.46 & $13 \cdot 28$ & $2 \cdot 19$ & $13 \cdot 15$ & 1.77 \\
\hline TSF at first visit $(\mathrm{mm})^{*}$ & 84.30 & $25 \cdot 31$ & 125.02 & $22 \cdot 76$ & $158 \cdot 74$ & 21.52 & 117.09 & $40 \cdot 19$ \\
\hline Fat mass $(\mathrm{kg})$ at first visit & $16 \cdot 5$ & 3.6 & $24 \cdot 6$ & 3.9 & $36 \cdot 1$ & 5.9 & 24.5 & 9.9 \\
\hline Length of gestation (weeks) & 39.5 & 1.4 & 39.0 & 1.7 & $39 \cdot 0$ & 1.3 & $39 \cdot 0$ & 1.7 \\
\hline Infant birth weight $(\mathrm{g})$ & 3331.5 & $481 \cdot 7$ & 3423.7 & $543 \cdot 2$ & $3670 \cdot 4$ & 489.5 & 3443.0 & $589 \cdot 60$ \\
\hline Placenta weight $(\mathrm{g})$ & 594.2 & 140.5 & 608.5 & $120 \cdot 4$ & $661 \cdot 7$ & 116.4 & $619 \cdot 1$ & 135.8 \\
\hline
\end{tabular}

* TSF, total skinfold thickness (sum of skinfold thicknesses: triceps, biceps, subscapular, suprailiac and mid thigh).

\section{Anthropometric values}

Total weight gain and fat gain from 13- to 36-weeks gestation $(n 77)$ were $10.9(\mathrm{SD} 4.7) \mathrm{kg}$ and $4.6(\mathrm{SD} 3.3) \mathrm{kg}$ $(P<0.001)$ respectively. Rate of fat gain was significantly higher in earlier stages of pregnancy (from 13 to 25 weeks) than the late pregnancy ( 25 to 36 weeks gestation) $(0 \cdot 3$ (SD $0.2)$ v. $0 \cdot 1(\mathrm{SD} 0 \cdot 2) \mathrm{kg} /$ week, $P=0 \cdot 001)$. Nevertheless, the rate of weight gain was not significantly different between these two compared stages of pregnancy $(0 \cdot 5$ (SD $0 \cdot 3)$ and $0.4(\mathrm{SD}$ $0 \cdot 3)$ at 13 - and 36-weeks gestation respectively, $P=0 \cdot 16)$.

At 6-weeks postpartum, maternal body weight and fat mass were 2.7 (SD 5.0) $\mathrm{kg}$ and 3.5 (SD 3.6) kg greater than at 13-weeks gestation $(P<0 \cdot 001, n 51)$.

There was a significant increase in fat mass from 13-weeks gestation to 6-months postpartum $(2.6$ (SD 4.5$) \mathrm{kg}$, $P<0.001, n$ 47). The increased weight $(1 \cdot 1$ (SD 6.0) kg,
$P=0 \cdot 2, n 47)$ at 6-months postpartum, however, was not statistically significant.

\section{Comparison of the body-mass-index groups}

The study population was also divided into different groups based on their early-pregnancy BMI. The individual plots of weight and fat mass changes during pregnancy and up to 6-months postpartum in each BMI group can be seen in Figs. 1 and 2 respectively. The pattern of weight changes follows a monotonous trend in normal weight individuals. They all seem to increase their weight during pregnancy and a considerable weight loss is observed at 6-weeks postpartum. From then to 6-months postpartum, they either tend to reduce slightly or stay at the same level. OW women show a divergent pattern. Individuals with the maximum weight gain and also the maximum weight loss are seen in
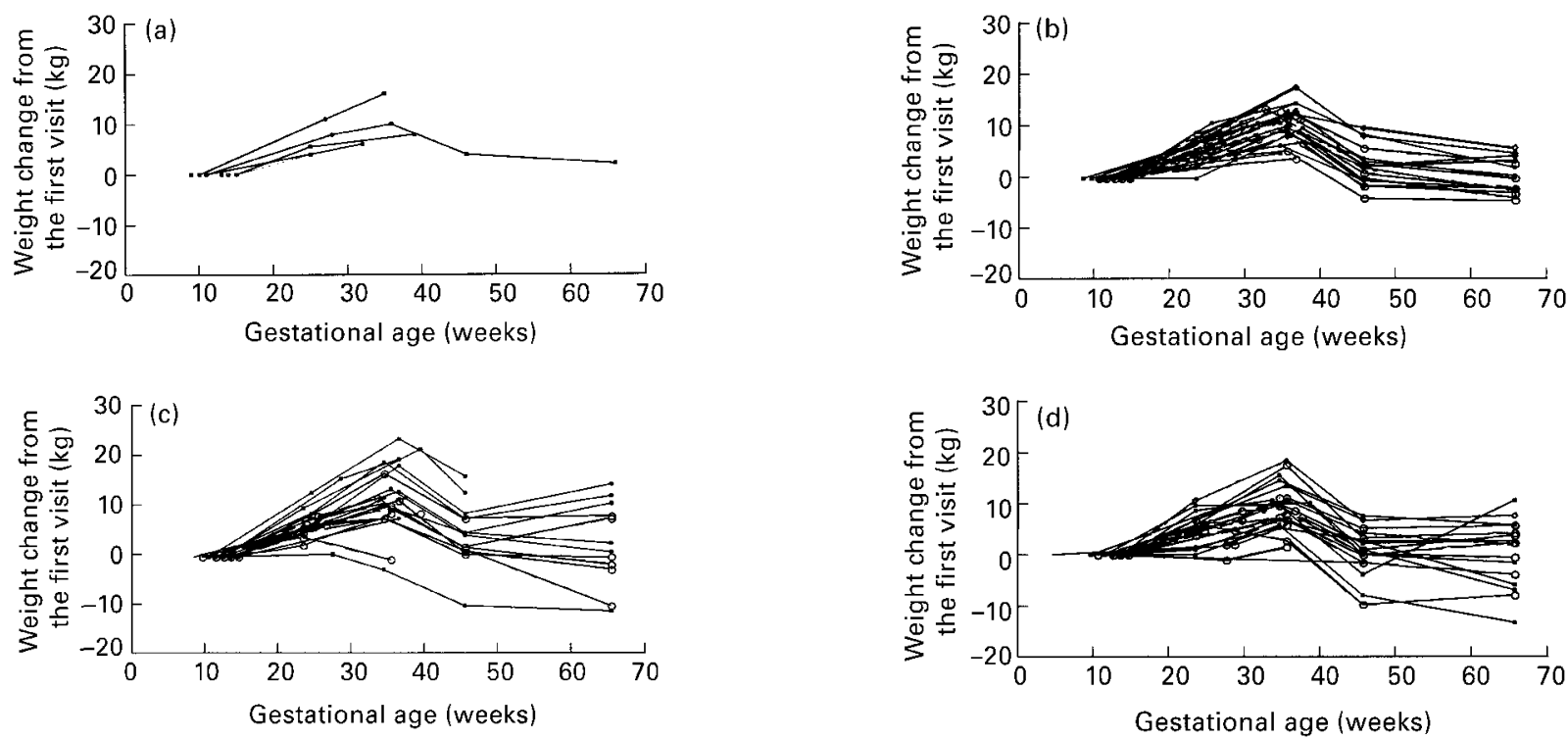

Fig. 1. Individual plots of weight changes during pregnancy and postpartum in four classified BMI groups: (a) underweight, (b) normal weight, (c) overweight, (d) obese. The changes are expressed as the difference of the measured values at each stage from the first visit value. 

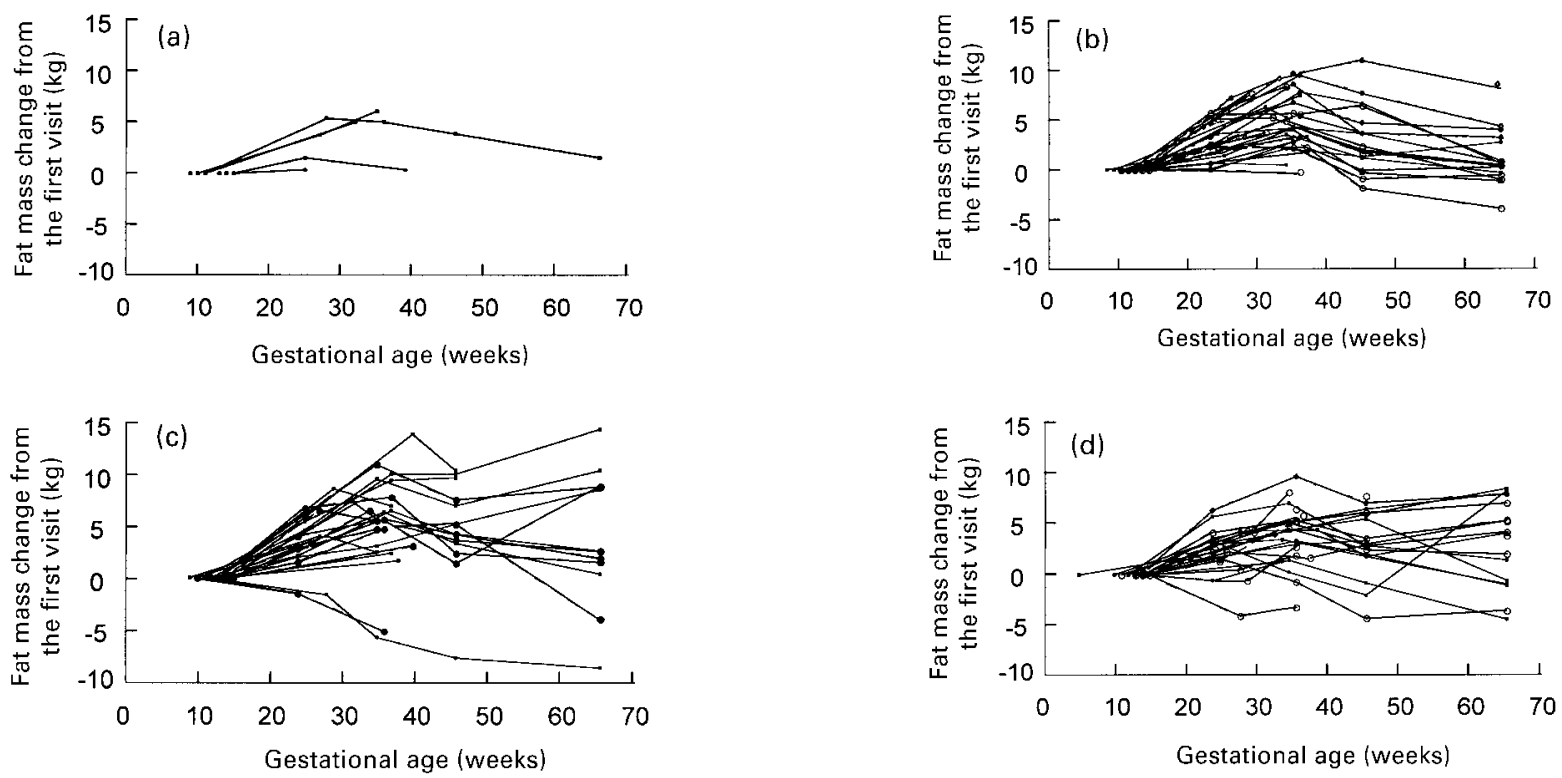

Fig. 2. Individual plots of fat mass changes during pregnancy and postpartum in four classified BMI groups: (a) underweight, (b) normal weight, (c) overweight, (d) obese. Fat mass changes are expressed as the difference of the values at each stage from the first visit values.

this group. The majority of $\mathrm{OB}$ women seem to be considerably heavier at 6-months postpartum in comparison with 13-weeks gestation. Similarly, in Fig. 2, NW women follow a comparatively monotonous pattern of changes in fat mass, the OW show a very scattered pattern and the OB women mostly have higher values of fat mass at 6-months postpartum than early pregnancy. There were only a few subjects in the UW group. This small group however, showed a similar trend of change to the NW group.

As there was a small number of subjects in the UW group, only three groups of NW, OW and OB were included in the statistical analysis. The results of one-way ANOVA suggested that there was no significant difference between the groups with respect to maternal age, parity, gestational age, and rate of breastfeeding, smoking and social class (based on maternal occupation). Rate of fat and weight changes were not significantly different between the groups in any stage of early or late pregnancy. As is evident in Table 3, the OB group proved to be significantly different from the NW group in the amount of fat loss from late pregnancy to 6-months postpartum.

\section{Direct interpretation of skinfold thickness changes}

Fig. 3 shows the average changes of each skinfold thickness (triceps, biceps, subscapular, suprailiac and mid thigh) from the value at the first visit for the groups of NW, OW and $\mathrm{OB}$ subjects. The most labile one is the suprailiac skinfold thickness, which seems to increase relatively more than the others in all the groups during pregnancy, but there is a different pattern of changes at the postpartum period. At this site, again the $\mathrm{OB}$ women showed the highest increase through the whole course of the study (13-weeks gestation to 6-months postpartum) and the least decrease during the postpartum period. The change in this skinfold thickness, however, was not significantly different between the groups over the pregnancy period (13-weeks to 36-weeks gestation).

The changes in the total skinfold thickness (sum of five skinfold thicknesses mentioned earlier) are presented in Table 4. From the comparison of the selected summary measures of total skinfold thickness, the OB group was significantly different from the NW group in respect to

Table 3. Observed changes in maternal fat mass and weight during and after pregnancy; comparison between groups of normal weight, overweight and obese women

(Mean values and standard deviations)

\begin{tabular}{|c|c|c|c|c|c|c|c|c|c|c|c|c|c|}
\hline \multirow[b]{3}{*}{ Groups† } & \multirow[b]{3}{*}{$n$} & \multicolumn{6}{|c|}{$\Delta$ Fat mass $(\mathrm{kg})$} & \multicolumn{6}{|c|}{$\Delta$ Body weight $(\mathrm{kg})$} \\
\hline & & \multicolumn{2}{|c|}{$A-C$} & \multicolumn{2}{|c|}{$A-E$} & \multicolumn{2}{|c|}{ C-E } & \multicolumn{2}{|c|}{$A-C$} & \multicolumn{2}{|c|}{$A-E$} & \multicolumn{2}{|c|}{$\mathrm{C}-\mathrm{E}$} \\
\hline & & Mean & $\mathrm{SD}$ & Mean & $\mathrm{SD}$ & Mean & $\mathrm{SD}$ & Mean & SD & Mean & $\mathrm{SD}$ & Mean & SD \\
\hline Normal weight & 29 & 4.9 & $2 \cdot 7$ & $1 \cdot 1$ & $2 \cdot 7$ & $-4 \cdot 1$ & $2 \cdot 1$ & 11.0 & 3.2 & 0.4 & 3.2 & $-10 \cdot 7$ & 2.5 \\
\hline Overweight & 23 & $5 \cdot 3$ & 4.5 & 3.9 & $6 \cdot 5$ & $-1 \cdot 1$ & $4 \cdot 3$ & 11.9 & $6 \cdot 4$ & $2 \cdot 8$ & 8.4 & $-8 \cdot 8$ & $5 \cdot 0$ \\
\hline Obese & 25 & 3.7 & $2 \cdot 8$ & 3.2 & 4.1 & $-0.9^{*}$ & 3.9 & 9.7 & 4.3 & 0.6 & 6.4 & -9.7 & 5.4 \\
\hline Total & 27 & 4.6 & $3 \cdot 4$ & 2.6 & 4.5 & $-2 \cdot 4$ & 3.8 & $10 \cdot 8$ & $4 \cdot 7$ & $1 \cdot 1$ & $6 \cdot 0$ & -9.9 & 4.4 \\
\hline
\end{tabular}

A, 13-weeks gestation; C, 36-weeks gestation; E, 6-months postpartum.

Mean value was significantly different from the normal weight group: * $P<0.05$

$\dagger$ Number of subjects at the postpartum (A-E and C-E) $n 47$ (normal weight $n$ 18, overweight $n$ 12, obese $n$ 17). 

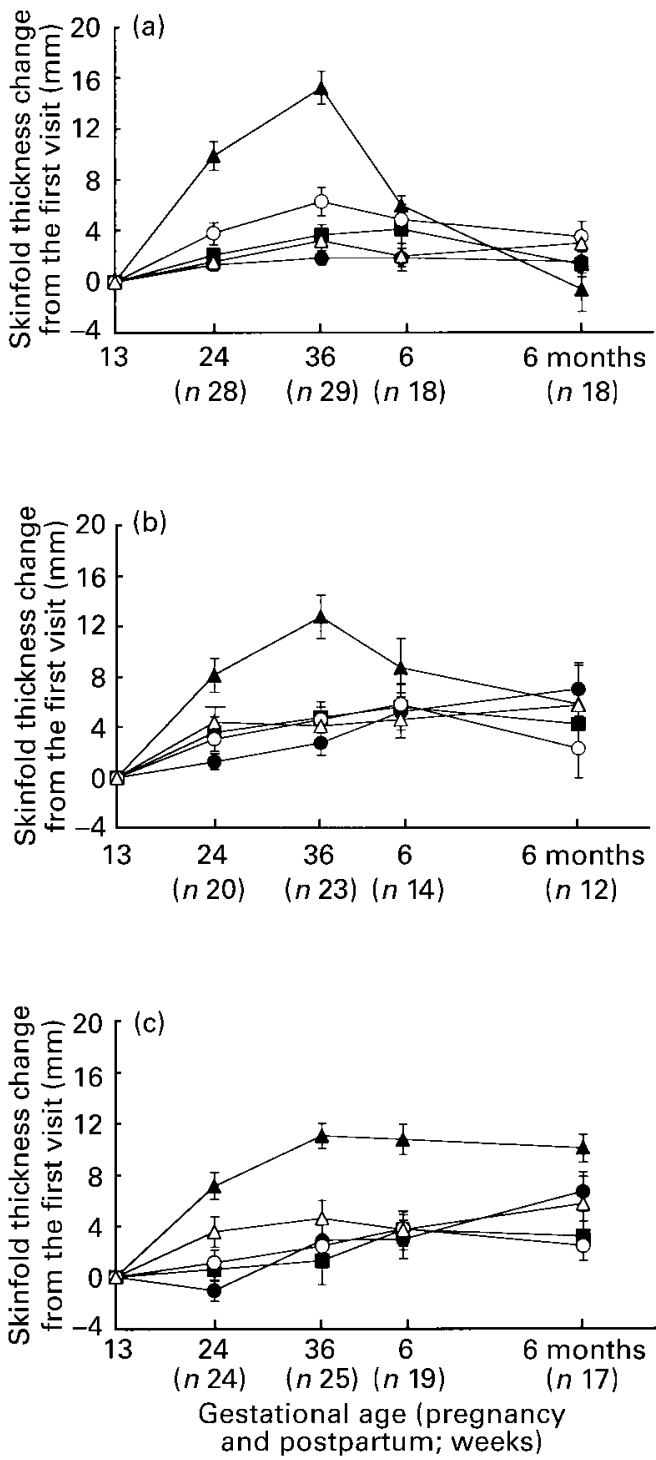

Fig. 3. Changes in five measured skinfold thicknesses (biceps, subscapular, suprailiac, mid thigh and triceps) during pregnancy and postpartum in groups of (a) normal weight, (b) overweight and (c) obese women. The changes are expressed as the difference of the mean values at each stage from the first visit value and standard errors of the mean represented by vertical bars. ( $\bullet$ ), Biceps; $(\boldsymbol{\square})$, subscapular; $(\mathbf{\Lambda})$ suprailiac; $(\bigcirc)$, mid thigh; $(\triangle)$, triceps. changes from 36-weeks gestation to 6-months postpartum. Whilst NW and OW women tended to have a reduction of total skin fold thickness, the OB group showed a mean increase in total skinfold thickness at the postpartum period.

The changes in waist : hip ratio from 6-weeks to 6-months postpartum were also compared between the three BMI groups. The results for each group of $\mathrm{NW}, \mathrm{OW}$ and $\mathrm{OB}$ are as follows: -0.02 (SD 0.05), 0.01 (SD 0.03), 0.02 (SD 0.03) respectively. The changes in the $\mathrm{OB}$ group were significantly different from the NW group in respect of this index of fat distribution $(P<0 \cdot 05)$.

\section{Discussion}

Studies on maternal anthropometric changes during pregnancy and the postpartum period are important for three main reasons. First to estimate energy requirements during pregnancy, second to evaluate the effect of these changes on fetal growth and finally to investigate the impact of childbearing on development of obesity. The last is the subject of our present study.

Relatively few observational studies have focused on the maternal fat changes during pregnancy and postpartum (Durnin, 1987; Forsum et al. 1988; Sadurskis et al. 1988; Van Raaij et al. 1989; Sohlström et al. 1993). Published results on fat gain during pregnancy show considerable variations. The extent of variation in the studies mentioned earlier is about $4 \mathrm{~kg}$. Possible explanations include: methodological variations, variation in the design of the studies (the interval between the measurements has been designed differently) and inter-subject variation. As for the first issue (methodological variations), because of the limited knowledge on the actual changes occurring during pregnancy on maternal tissue and also the limitation of the methodology of body composition measurements (e.g. densitometry, total body $\mathrm{K}$, total body water, skinfold thickness measurements, bioelectrical impedance) it is difficult to judge the validity of the methods. Multicompartment methods are more reliable, however, there is problem of access to more expensive and complicated techniques. Bearing in mind the method-related limitations, it seems to be appropriate for population studies to use the simple methods which are practically more acceptable and feasible. Therefore, for a reasonably high number of subjects (such as our present study) it seemed appropriate to use

Table 4. Changes in total skinfold thicknesses; comparison between groups of normal weight, overweight and obese women during and after pregnancy

\begin{tabular}{|c|c|c|c|c|c|c|c|}
\hline \multirow[b]{3}{*}{ Group† } & \multirow[b]{3}{*}{$n$} & \multicolumn{6}{|c|}{$\Delta \mathrm{TSF}(\mathrm{mm})$} \\
\hline & & \multicolumn{2}{|c|}{$A-C$} & \multicolumn{2}{|c|}{$A-E$} & \multicolumn{2}{|c|}{ C-E } \\
\hline & & Mean & SD & Mean & SD & Mean & SD \\
\hline $\begin{array}{l}\text { Normal weight } \\
\text { Overweight } \\
\text { Obese }\end{array}$ & $\begin{array}{l}29 \\
23 \\
25\end{array}$ & $\begin{array}{l}30 \cdot 26 \\
28 \cdot 82 \\
22 \cdot 20\end{array}$ & $\begin{array}{l}18.61 \\
24.97 \\
17.86\end{array}$ & $\begin{array}{r}8.74 \\
24 \cdot 10 \\
28 \cdot 04\end{array}$ & $\begin{array}{l}15.77 \\
38.68 \\
19.18\end{array}$ & $\begin{array}{c}-23.96 \\
-9.48 \\
3.93^{*}\end{array}$ & $\begin{array}{l}14.85 \\
28.49 \\
22 \cdot 03\end{array}$ \\
\hline
\end{tabular}

A, 13-weeks gestation; C, 36-weeks gestation; E, 6-months postpartum; TSF, total skinfold thickness (sum of triceps, biceps, subscapular, suprailiac and mid thigh).

Mean value was significantly different from the normal weight group: * $P<0.05$

† Number of subjects at the postpartum (A-E and C-E) $n 47$ (normal weight $n 18$, overweight $n 12$, obese $n 17$ ). 
the skinfold thickness measurement method using adjusted formulas for gestational alterations. As for the issue of intersubject variation, factors like original maternal BMI have not been particularly considered in the analysis of the data in any of the studies mentioned earlier. The subjects were either selected as normal weight, which therefore could not be representative of a typical population, or BMI was not mentioned in the table of characteristics of the subjects. In our present study, women were classified based on their early pregnancy BMI and then were compared in various anthropometric measurements. Total fat gain was not significantly different between the subjects in different BMI groups during pregnancy.

Total fat gain during pregnancy in our present study (4.6 $($ SD 3.3$) \mathrm{kg}$ ) was similar to the results of Forsum et al. (1988) $(4.5 \mathrm{~kg})$, Sadurskis et al. (1988) $(5.8(\mathrm{SD} 4 \cdot 2) \mathrm{kg})$ and the findings of Sohlström et al. (1993) $(5 \cdot 5$ (SD 3.2) kg) during a full-term pregnancy. It was however a higher figure than the findings of Van Raaij et al. (1989) (2.0 (SD 2.6)) or Durnin (1987) $(2 \cdot 1 \mathrm{~kg})$.

Measurement of maternal weight changes during pregnancy and the postpartum period suffers less from the lack of accuracy and being methodologically simpler, has been the subject of many investigations. Considering the period of the study, total gestational weight gain in our study (10.9 $(\mathrm{SD} 4.7) \mathrm{kg}$ ) is consistent with other studies: Durnin (1987), from 10-40 weeks $11.7 \mathrm{~kg}$; Sadurskis et al. (1988), over whole pregnancy $13.8 \mathrm{~kg}$; Van Raaij et al. (1989), over whole pregnancy 11.8 (SD 3.7) $\mathrm{kg}$. In our present study, extremes of weight and fat changes were most marked in the OW and the OB groups.

In terms of postpartum weight retention, important contributing elements are believed to be gestational weight gain, maternal age, parity, lifestyle factors and initial maternal weight (Lederman et al. 1993). Except for maternal weight, our BMI groups were matched in all of the factors mentioned earlier (it should be mentioned that from the lifestyle factors, data on smoking and social class (based on maternal occupation) were available). From 36-weeks gestation to 6-months postpartum, there was no significant difference in weight changes, however, a significant difference was observed between the OB and NW groups in the amount of fat loss at the postpartum period. This observation was also confirmed by the direct interpretation of skinfold thickness changes and circumference measurements. There was a significant difference between the $\mathrm{OB}$ and the NW in terms of the changes in total skinfold thickness and suprailiac skinfold thickness changes.

Our present results suggest that although pregnancy may not have an obvious effect on postpartum weight retention, as has been concluded in review by Lederman et al. (1993), there could be a significant tendency in the OB women to develop central fat retention. This is of considerable importance because an increased central fat distribution represented by an increased waist: hip ratio is shown to be the most valid anthropometric index for identifying individuals whose obesity predispose them to glucose intolerance (McKeigue et al. 1992). Sohlström \& Forsum (1995), in a study of the changes and distribution of adipose tissue volume during reproduction in fifteen Swedish women using magnetic resonance imaging, also showed that adipose tissue volume remaining at 6 months and 1 year after delivery tend to be localized centrally. It should be noticed that the confounding effect of BMI was not considered in the design of their study.

The results of our present study are reassuring for women classified as NW or OW, in the sense that pregnancy did not appear to have any significant effect on the retention of weight or fat at the postpartum period. Our findings are useful in that we have identified the most vulnerable group; our findings could be an essential background for the design of postpartum interventional studies addressed to reduction in obesity and diabetes risk. Further research is required to investigate the long-term changes as well as the effect of lactation on the pattern of maternal body composition alteration at the postpartum period in each BMI group.

\section{References}

Department of Health (1997) Health of the Nation. A Progress Report. Public Accounts Committee 17th Report. London: The Stationery Office.

Durnin JVGA (1987) Energy requirements of pregnancy: an integration of longitudinal data from the five-country study. Lancet ii, 1131-1133.

Durnin JVGA \& Womersley J (1974) Body fat assessed from total body density and its estimation from skinfold thickness: measurements on 481 men and women aged from 16 to 72 years. British Journal of Nutrition 32, 77-97.

Forsum E, Sadurskis A \& Wager J (1988) Resting metabolic rate and body composition of healthy Swedish women during pregnancy. American Journal of Clinical Nutrition 47, 942-947.

Harris HE \& Ellison GT (1997) Do the changes in energy balance that occur during pregnancy predispose parous women to obesity? Nutrition Research Reviews 10, 57-81.

Harris HE, Ellison GTH, Holliday M \& Lucassan E (1997) The impact of pregnancy on the long term weight gain of primiparous women in England. International Journal of Obesity 21, 747-757.

Institute of Medicine (1990) Nutrition During Pregnancy: Weight Gain and Nutrient Supplement. Washington, DC: National Academy Press.

Jung RT (1997) Obesity as a disease. British Medical Bulletin 53, 307-321.

Kissebah AH \& Krakower GR (1994) Regional adiposity and morbidity. Physiological Reviews 74, 761-809.

Lederman SA, Pierson RN, Wang J, Paxton A, Thornton J, Wendel J \& Heymsfield SB (1993) Body composition measurements during pregnancy. Basic Life Science 60, 193-195.

McKeigue PM, Pierpoint T, Ferrie JE \& Marmot MG (1992) Relationship of glucose intolerance and hyperinsulinaemia to body fat patterns in south Asians and Europeans. Diabetologia 35, 785-791.

Matthews J, Altman DG, Campbell MJ \& Royston P (1990) Analysis of serial measurements in medical research. British Medical Journal 300, 230-235.

Muscati SK, Graydonald K \& Koski KG (1996) Timing of weight gain during pregnancy, promoting fetal growth and minimizing maternal weight retention. International Journal of Obesity Related Metabolic Disorders 20, 526-532.

Office of Population Censuses and Surveys (1991) Census of Great Britain 2, 40-41.

Ohlin A \& Rossner S (1990) Maternal body weight development after pregnancy. International Journal of Obesity 14, 159-173.

Sadurskis A, Kabob N, Wager J \& Forsum E (1988) Energy metabolism, body composition, and milk production in healthy 
Swedish women during lactation. American Journal of Clinical Nutrition 48, 44-49.

Siri WE (1956) The gross composition of the body. In Advances in Biological and Medical Physics, pp. 239-280 [CA Tobias and JH Lawrence, editors]. New York, NY: Academic Press.

Sohlström A \& Forsum E (1995) Changes in adipose tissue volume and distribution during reproduction in Swedish women as assessed by magnetic resonance imaging. American Journal of Clinical Nutrition 61, 287-295.

Sohlström A, Whaled L \& Forsum E (1993) Total body fat and its distribution during human reproduction as assessed by magnetic resonance imaging. In Human Body Composition, pp. 181-184 [KJ Ellis and JD Eastman, editors]. New York, NY: Polonium Press.

Solomon CG, Willett WC, Carey VJ, Rich-Edwards J, Hunter DJ, Colditz GA, Stampfer MJ, Speizer FE, Spiegelman D \& Manson JE (1997) A prospective study of pregravid determinants of gestational diabetes mellitus. Journal of the American Medical Association 278, 1078-1083.

Taggart NR, Holliday RM, Billewicz WZ, Hytten FE \& Thompson AM (1967) Changes in skinfolds during pregnancy. British Journal of Nutrition 21, 439-451.

Van Raaij JMA, Peek MEM, Vermaat-Miedema SH, Schnock CM \& Hautvast JGAJ (1988) New equations for estimating body fat mass in pregnancy for body density or total body water. American Journal of Clinical Nutrition 48, 24-29.

Van Raaij JMA, Schnock CM, Vermaat-Miedema SH, Peek MEM \& Hautvast JGAJ (1989) Body fat mass and basal metabolic rate in Dutch women before, during and after pregnancy: a reappraisal of energy cost of pregnancy. American Journal of Clinical Nutrition 49, 765-772.

World Health Organization (1987) Report on a WHO Consultation on the Epidemiology of Obesity: Measuring Obesity-classification and Description of Anthropometric Data. Copenhagen and Warsaw: WHO. 